\title{
Dispositivos móveis em museus: proporcionando novas experiências com o uso de recursos de georreferenciamento
}

\section{Mobile devices in museums: providing new experiences using geolocation}

\author{
Eveline Helena Almeida de Souza ${ }^{1}$
}




\section{Resumo}

A pesquisa apresentada neste artigo teve como objetivo investigar o uso de recursos tecnológicos no espaço museal, em específico os sistemas de georreferenciamento em dispositivos móveis, e de que forma eles podem contribuir para uma melhora na experiência de visita a museus. Buscou-se conhecer um pouco mais sobre o visitante de museus $\mathrm{e}$ sua interação com o ambiente expositivo por meio de técnicas de pesquisa no âmbito da Interação Humano-Computador.

Palavras-chave: museus; ubiquidade; georreferenciamento; design de interação.

\section{Abstract}

The research presented in this article intends to analyze the use of technology inside the museum, particularly the use of location based services for mobile devices. The purpose of the project is to investigate whether this type of technology can contribute to a better museum experience. In order to identify visitors issues and needs, analyzing their interaction with the museum digital interfaces, were used techniques in the Human Computer Interaction field.

Keywords: museums; ubiquity; location based services; interaction design. 


\section{Introdução}

De instituições responsáveis pela conservação da memória e da cultura material, à perspectiva atual de produção e transmissão de conhecimento, os museus têm passado por verdadeiras metamorfoses ao longo de sua história. Atualmente, além da missão pedagógica, representam também espaços de aprendizagem informal, onde cultura, tecnologia e entretenimento caminham lado a lado.

Essas mudanças ocorridas no museu refletem as profundas transformações sociais vistas nas últimas décadas, onde a utilização da tecnologia como meio de criação de conhecimento desempenha um papel fundamental nas atividades econômicas e culturais (ANASTÁCIO, 2009). Esse profundo contato com a tecnologia fez com que a percepção humana de espaço fosse ampliada, levando as pessoas a deixarem para trás o tradicional papel de receptor, assumindo assim o papel de emissor, o que resultou em novas formas de se conceber o pensamento (AMARAL, 2003).

Neste mundo "[...] marcado pela desconstrução das noções tradicionais de tempo e de espaço, no qual identidades locais e globais se relacionam em complementaridade" (INSTITUTO BRASILEIRO DE MUSEUS, 2012), os museus se veem diante do desafio de refletir sobre seu papel na sociedade neste início de século XXI. (COSTA SANTOS \& LIMA, 2014)

As novas tecnologias, em particular os dispositivos móveis, são vistos como importantes instrumentos no processo de comunicação entre o museu e seu público, promovendo novas formas de acesso à informação (MENEZES, 2011). Eles fornecem flexibilidade na apresentação do conteúdo, sendo possível atingir diferentes tipos de visitantes, atentando-se à forma de apreensão de informação de cada um, respeitando suas limitações e suas capacidades cognitivas, possibilitando assim uma democratização do espaço expositivo.

Diante desse cenário, a pesquisa descrita neste artigo propôs-se a verificar se o uso de dispositivos móveis no ambiente expositivo pode auxiliar o visitante a ter uma melhor compreensão da exposição.

Apesar da pesquisa realizada ter apresentado um objetivo mais abrangente, 0 foco deste artigo é descrever apenas as características do projeto que estejam relacionadas com a utilização de ferramentas de georreferenciamento e como elas podem contribuir para uma melhor experiência de visita ao museu.

\section{Museus e tecnologia}

\subsection{A tecnologia no espaço expositivo}

A necessidade em se adaptar aos novos paradigmas socioculturais do século $X X I$, fez com que o museu buscasse na tecnologia soluções que permitam uma melhor interação do visitante com a exposição, ao mesmo tempo em que visa alcançar públicos mais diversos (VAZ, 2014). Além disso a tecnologia também auxilia os profissionais de museu a conhecerem melhor seus visitantes, facilitando a transmissão do conhecimento. Assim, a comunicação é ampliada para além do espaço expositivo, 
proporcionando uma maior autonomia e flexibilidade ao visitante, permitindo a seleção de percursos museológicos alternativos e interativos. Dessa forma, cada indivíduo pode ter sua própria experiência ao escolher como e quando interagir.

O visitante transforma-se num espectador activo, possibilitando-lhe a tomada de decisões, a escolha do que quer aprender, desencadeando mecanismos físicos, mentais e emocionais, que lhe permitem compreender as mensagens e os conceitos que a instituição pretende transmitir. (AMARAL, 2003, p. 44)

Apesar de todas essas vantagens, a tecnologia pode dificultar a apreensão da informação caso o foco da atenção dos visitantes seja voltado apenas para os dispositivos tecnológicos, e não para a exposição como um todo. Isso pode vir a prejudicar inclusive as relações interpessoais, servindo como uma forma de distração. No entanto, mesmo que represente uma certa forma de isolamento, esses recursos podem ser de grande benefício se projetados tendo como foco o usuário e sendo utilizados de modo correto pelo museu (KRUK, 2015).

\subsection{Ubiquidade e Interatividade}

Dentre as inovações tecnológicas encontradas em espaços expositivos pode-se destacar o uso da ubiquidade, que permite aos usuários autonomia e mobilidade no espaço (BALLARD, 2007). Num sistema ubíquo a pessoa pode interagir com qualquer dispositivo eletrônico presente no ambiente, e esses aparelhos têm a capacidade de se comunicar entre si. Essa forma de interação configura a chamada Internet das Coisas $^{1}$,

Dentre as tecnologias mais relevantes da ubiquidade podemos destacar os serviços de georrefereciamento ou geolocalização, que consistem em determinar a posição espacial de um sistema conectado em rede. Um dos serviços mais populares desse tipo de tecnologia é o GPS (global positioning system), que determina a posição espacial utilizando um conjunto de satélites. Contudo, o GPS não apresenta a mesma precisão em ecossistemas fechados, sendo para isso utilizadas outras tecnologias como, por exemplo, o bluetooth, que consiste em uma rede sem fio gerada entre um ou mais dispositivos dispostos em um espaço delimitado (NING, 2015).

Em ambientes fechados geralmente é utilizado o Bluetooth Low Energy (BLE), que é similar ao bluetooth tradicional, porém oferece menor custo, menor consumo de energia e dispositivos em tamanhos mais compactos. Os sensores mais comuns são os chamados beacons, que consistem em pequenos aparelhos que transmitem sinais via BLE, e são transmitidos em pacotes de dados, sendo assim identificados pelos dispositivos eletrônicos presentes no ambiente. (BENÍCEK, 2015)

Diante desse cenário, os dispositivos móveis, sejam eles pessoais ou fornecidos pelo museu, estão cada vez mais sendo utilizados porque conjugam tudo o que já foi

1 "Internet of Things [...] is the general idea of things, especially everyday objects, that are readable, recognizable, locatable, addressable, and controllable via the Internet - whether via RFID, wireless LAN, wide-area network, or other means" (National Intelligence Council apud. Swan, 2012, p. 217) 
falado anteriormente: eles permitem liberdade ao visitante, tanto de poder se movimentar, como de adotar seu próprio percurso museológico, e também de escolher como e quando interagir e obter informação. São, inclusive, extremamente apropriados para a personalização da visita, permitindo que os visitantes configurem suas preferências pessoais, que o acompanharão durante todo o percurso.

A vantagem dos dispositivos móveis pessoais é que os usuários já estão acostumados com seus próprios aparelhos, tornando o aprendizado do sistema bem mais rápido do que se estivessem utilizando um aparelho de propriedade do museu. Nesse ponto isso até configura uma vantagem para os próprios museus que podem economizar enormemente no que tange à aquisição e à manutenção de aparelhos eletrônicos.

No entanto, há de se pensar também nas dificuldades que podem surgir na adoção de dispositivos móveis, tais como a limitação da duração da bateria, e o consumo de dados de internet, caso seja necessário baixar o aplicativo ou arquivos multimídia. Segundo Rung \& Laursen (2012), é preciso equilibrar a atenção do visitante entre dispositivo, possíveis companheiros, obras de arte e ambiente. Sua apreensão da informação é um processo complexo e exige um estudo abrangente por parte tanto dos curadores quanto dos designers.

\subsection{A interação do visitante no ambiente expositivo}

Segundo Kruk (2015), as decisões sobre o percurso e as narrativas museológicas de cada exposição são projetadas em função do público, o qual exerce um papel central no projeto museológico. Magaldi (2010, p.90) afirma "Quem faz do museu um museu é o público. Não existe museu sem público. O cotidiano cultural do público é que vai sustentar a interpretação." O museu oferece uma experiência, porém o público é quem constrói seu ritmo, que dá significado à mensagem recebida.

É necessário seduzir o público, conduzi-lo a se interrogar sobre seu ambiente. E quanto mais encantado e seduzido o público estiver, maior será a propensão do mesmo em querer repetir aquela experiência e incentivar outros a também participar. Contudo, encantar não significa apenas expor o acervo de forma diferente, pois as características subjetivas e cognitivas dos visitantes também estão envolvidas no processo. Para Amaral (2013, p.39) "a experiência mais transformadora que o indivíduo pode obter é aquela que suporta e/ou facilita os seus interesses e suas curiosidades intelectuais ao longo da vida."

Uma forma de cativar o público é se mostrar como um espaço sem preconceitos, onde o visitante comum é valorizado da mesma forma que o visitante especialista. Para tanto é necessário fornecer diferentes conteúdos e ferramentas interpretativas que possam ir de encontro às expectativas de cada um (KRUK, 2015).

A carga de conhecimentos e experiências anteriores dos visitantes pode gerar um impacto cognitivo, afetando sua forma de processar informação. Também ocorre um impacto afetivo, o que inclui as emoções, valores, energia, entre outros.

A fim de estabelecer uma comunicação com seu público, atentando para suas necessidades e dificuldades, um projeto museológico que utiliza recursos tecnológi- 
cos precisa ser centrado no visitante, utilizando-se de recursos que analisam a interação do público com as interfaces disponibilizadas e que levam em consideração a eficiência, a eficácia e uma boa experiência do usuário.

\section{Metodologia}

O objetivo principal desse estudo foi investigar se o uso de dispositivos móveis poderia facilitar o acesso à informação, auxiliando o visitante a ter uma melhor compreensão da exposição. Para tanto foram utilizadas as seguintes técnicas de pesquisa: observação sistemática, entrevistas e avaliação cooperativa. A seguir são descritos os principais pontos levantados na aplicação de cada técnica.

\subsection{Observação sistemática}

A fim de se observar a interação dos visitantes com o ambiente expositivo foi escolhida a técnica de observação sistemática. Ela consiste na compreensão de como determinada atividade é realizada, observando-se as etapas do processo, as ferramentas utilizadas, as dificuldades surgidas e os resultados do trabalho (GIL, 2008).

Foram definidas para a amostra, exposições de museus e centros culturais classificadas na tipologia "Imagem e Som", de acordo com a classificação do Instituto Brasileiro de Museus - IBRAM (2011), sendo aplicada em 5 museus da cidade do Rio de Janeiro: Museu Cidade Olímpica, Museu do Amanhã, Museu das Telecomunicações, CCBB/RJ e Museu de Arte do Rio.

A técnica foi aplicada entre agosto e setembro de 2016 e consistia na observação da interação dos visitantes com o espaço. Além disso, também foram analisados os recursos informativos e interativos encontrados e a infraestrutura do museu.

\subsection{Entrevistas}

A escolha da técnica de entrevistas teve como objetivo conhecer as necessidades e os desejos dos visitantes e identificar possíveis falhas no acesso à informação. Essa técnica consiste numa forma de diálogo assimétrico em que uma das partes busca coletar dados e a outra representa a fonte de informações (GIL, 2008).

As perguntas foram divididas em quatro blocos: interesses pessoais e hábitos culturais, acesso à informação, interatividade e dispositivos móveis, e experiência do visitante. Foi realizado um total de 14 entrevistas, sendo 3 consideradas como piloto e 11 como parte da pesquisa. As entrevistas foram realizadas nas duas últimas semanas de setembro de 2016.

\subsection{Avaliação Cooperativa}

Após a realização das duas técnicas anteriores - observação sistemática e entrevistas - surgiu a necessidade de se avaliar o nível de entendimento e satisfação dos usuários com relação ao uso de interface para dispositivo móvel. Para esse fim foi 
escolhida a técnica avaliação cooperativa que, segundo Moraes (2008), consiste na obtenção de dados sobre problemas encontrados ao utilizar determinada interface digital.

O aplicativo escolhido para os testes apresentava recursos de georreferenciamento por meio de sensores bluetooth, recursos de orientação espacial por meio de mapas e também alguns recursos simples de personalização, como registro de obras favoritas.

Ao todo foram realizados 8 testes, sendo 3 considerados como testes piloto. As avaliações foram realizadas na segunda semana de outubro de 2016 . Foi utilizada uma amostra por conveniência, e, apesar do pequeno número de participantes, foi possível selecionar perfis variados.

\section{Resultados}

Um ponto muito importante para o visitante de museus é sua orientação espacial. Como apontado nas pesquisas, não é raro sentir-se perdido dentro de uma exposição, especialmente em grandes museus. Durante as observações sistemáticas foi possível perceber que apenas um museu - o Museu do Amanhã - dispunha de mapas, tanto do prédio inteiro, como do percurso expositivo, e oferecia essa informação de forma impressa e também digital.

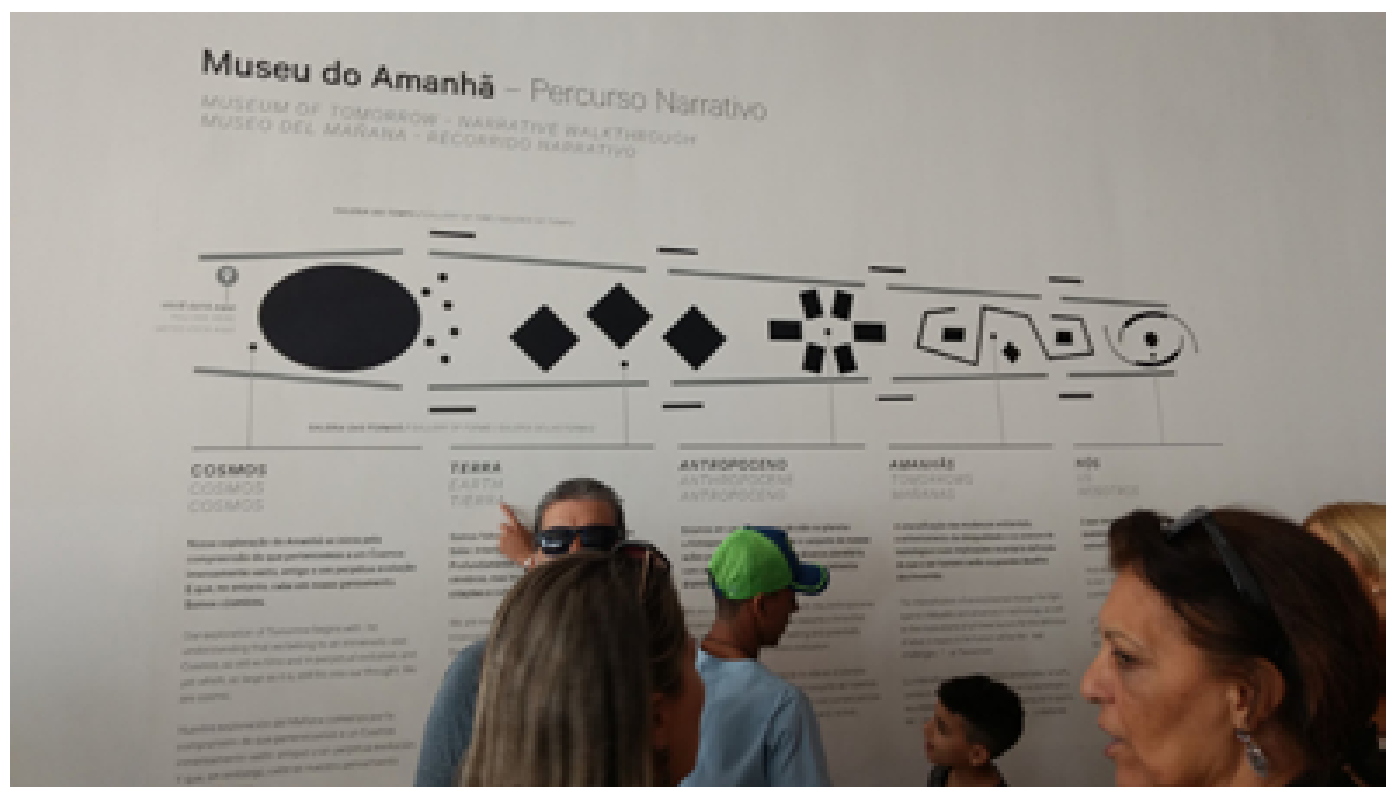

Figura 1: Mapa do percurso narrativo da Exposição Principal do Museu do Amanhã

Nas entrevistas, boa parte das sugestões dizia respeito à orientação espacial, solicitando a disponibilização de mapas, ou alguma outra forma de proporcionar maior controle do percurso narrativo. O uso de aplicativos móveis oferece uma vantagem nesse aspecto pois é possível se localizar no espaço em qualquer ponto do museu através do uso de sensores de georreferenciamento. É possível também incluir rotas e sugeri-las aos visitantes de acordo com sua localização atual, suas preferências ou por meio de seu histórico. 
Durante a aplicação das avaliações cooperativas, os participantes esperavam que o aplicativo fosse capaz de localizar sua posição no espaço e com isso utilizar melhor as funcionalidades de mapa e registro de obras visitadas. Essa expectativa demonstra o costume de se utilizar o recurso de localização como forma de personalização em dispositivos móveis.

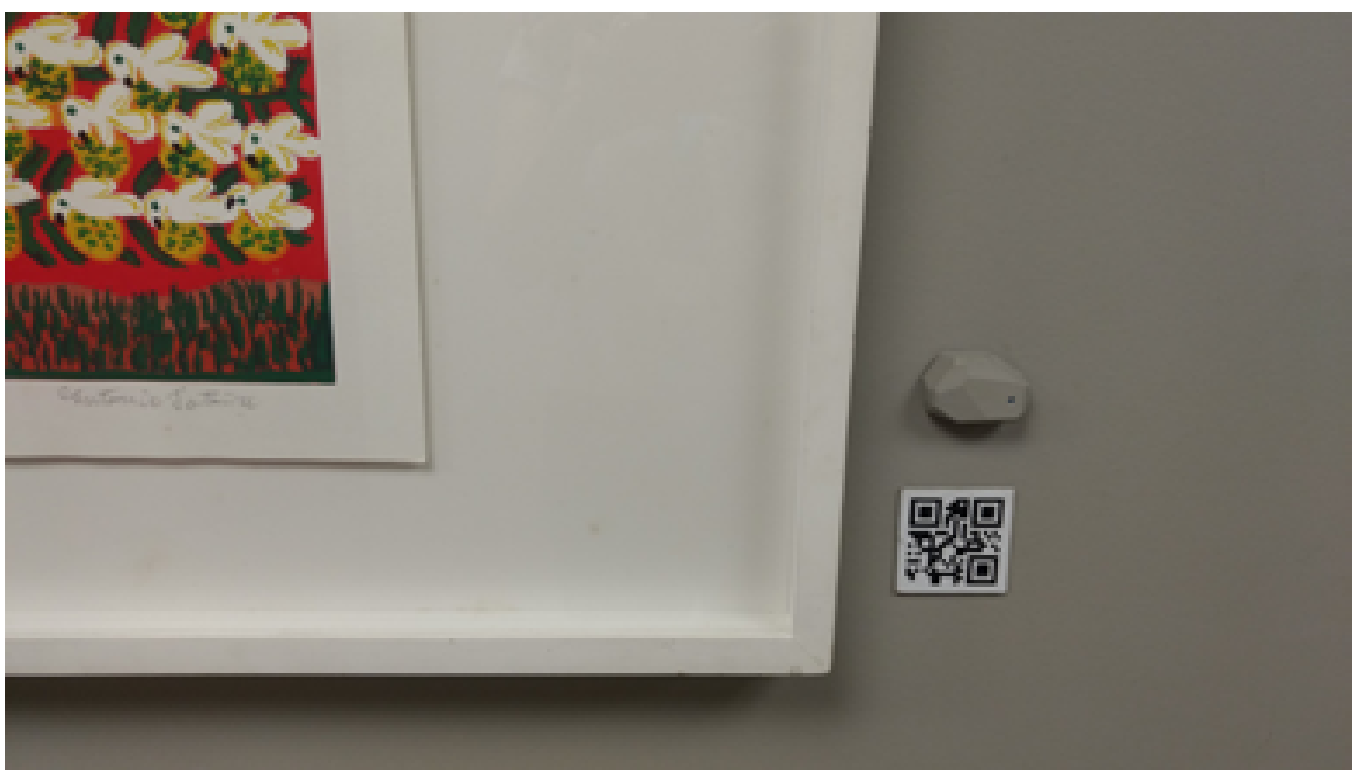

Figura 2: Posicionamento do sensor utilizado na avaliação cooperativa

Também é interessante o uso dos sensores como registro de histórico da visita, informando sobre o percurso realizado, e o que ainda pode ser visto na exposição. Encontrado no Museu do Amanhã durante as observações sistemáticas, esse recurso ainda permite descobrir sua localização no mapa e saber a porcentagem de conteúdo já visualizada na exposição. Contudo, não eram utilizados sensores, pois a posição do totem usado no momento que determinava a posição do visitante.

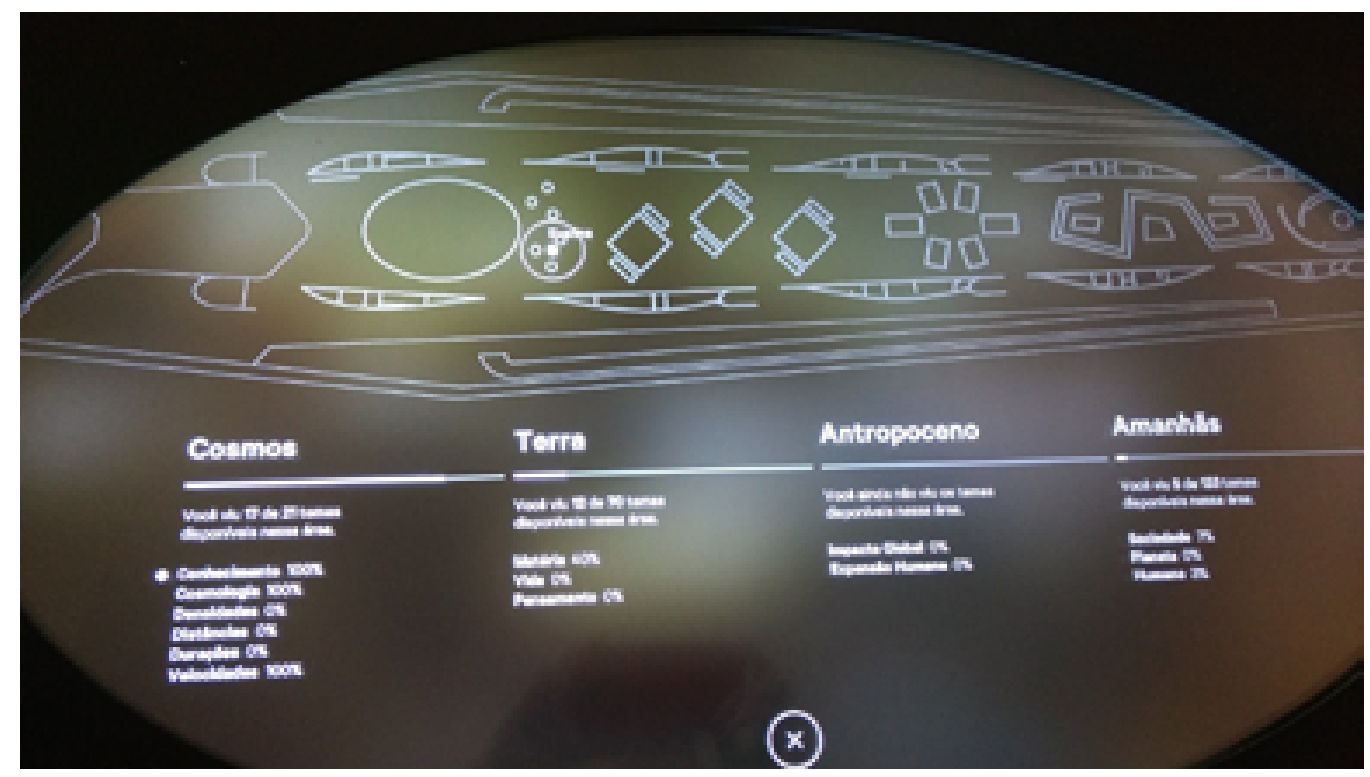

Figura 3: Totem exibindo mapa com indicação da localização e do histórico da visita 
Um dos usos mais interessantes encontrados, foi o do aplicativo para museus Flinckapp, analisado durante as pesquisas de benchmarking. Ao passar por uma área contendo sensores, os smartphones, com o aplicativo instalado e ativo, recebem informações ligadas ao contexto em que o visitante se encontra.

Por exemplo, ao se aproximar da obra Nightwacht (De Nacthwacht), Rembrandt van Rijn te adiciona como amigo. Você recebe mensagens pessoais dele, e também acompanha as conversas do artista com outras pessoas que viram sua obra ou com outros pintores da mesma sala. (LEPORACE, 2016)

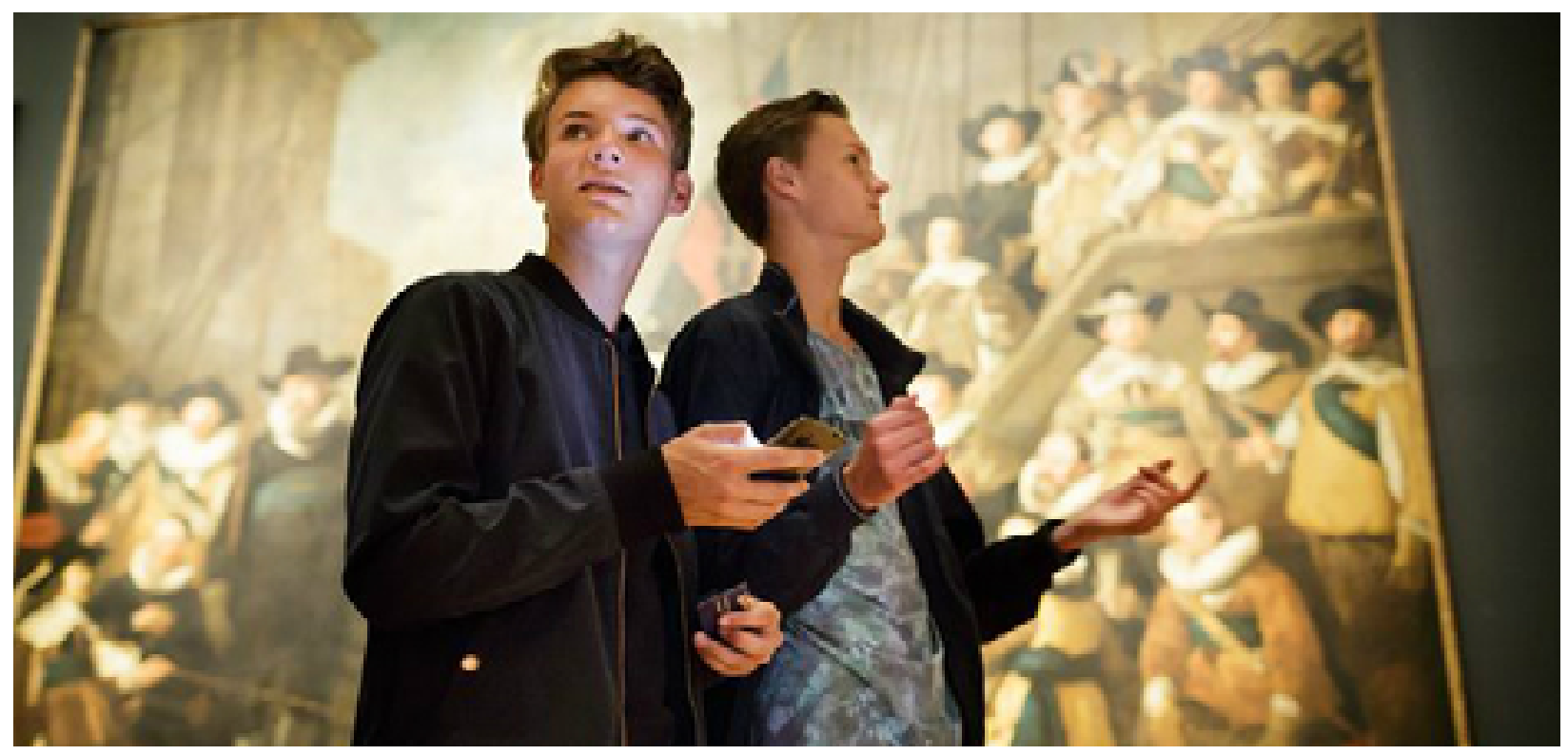

Figura 4: Visitantes interagindo com o aplicativo Flinckapp por meio de beacons

\subsection{Protótipo}

Após as análises das técnicas foi desenvolvido um protótipo de alta fidelidade para demonstrar visualmente algumas das soluções propostas para os desafios encontrados. Nele é proposto um aplicativo para dispositivos móveis que tem suas principais funcionalidades ativadas por meio de um sensor de georreferenciamento.

\subsection{Orientação espacial}

Uma das principais necessidades dos visitantes identificada durante as pesquisas foi a orientação espacial. Com o uso dos sensores, o aplicativo pode determinar a localização do visitante no ambiente expositivo. Além disso é possível fazer um registro das obras que já foram visitadas, por meio de um histórico de sensores ativados como é possível ver na figura 5(a). Também é possível sugerir diferentes rotas para a visita, a depender do tamanho da exposição, oferecendo ao visitante a possibilidade de escolha de percursos alternativos como visto na figura 5(b). 

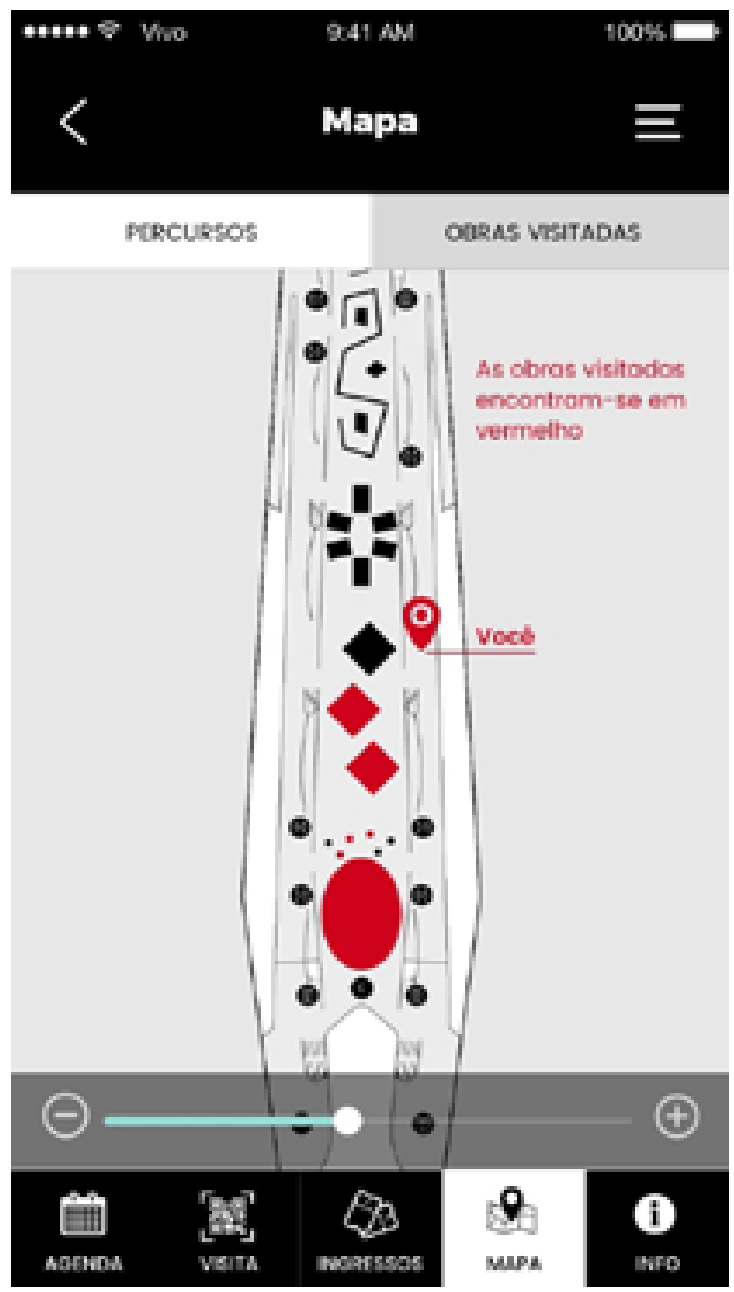
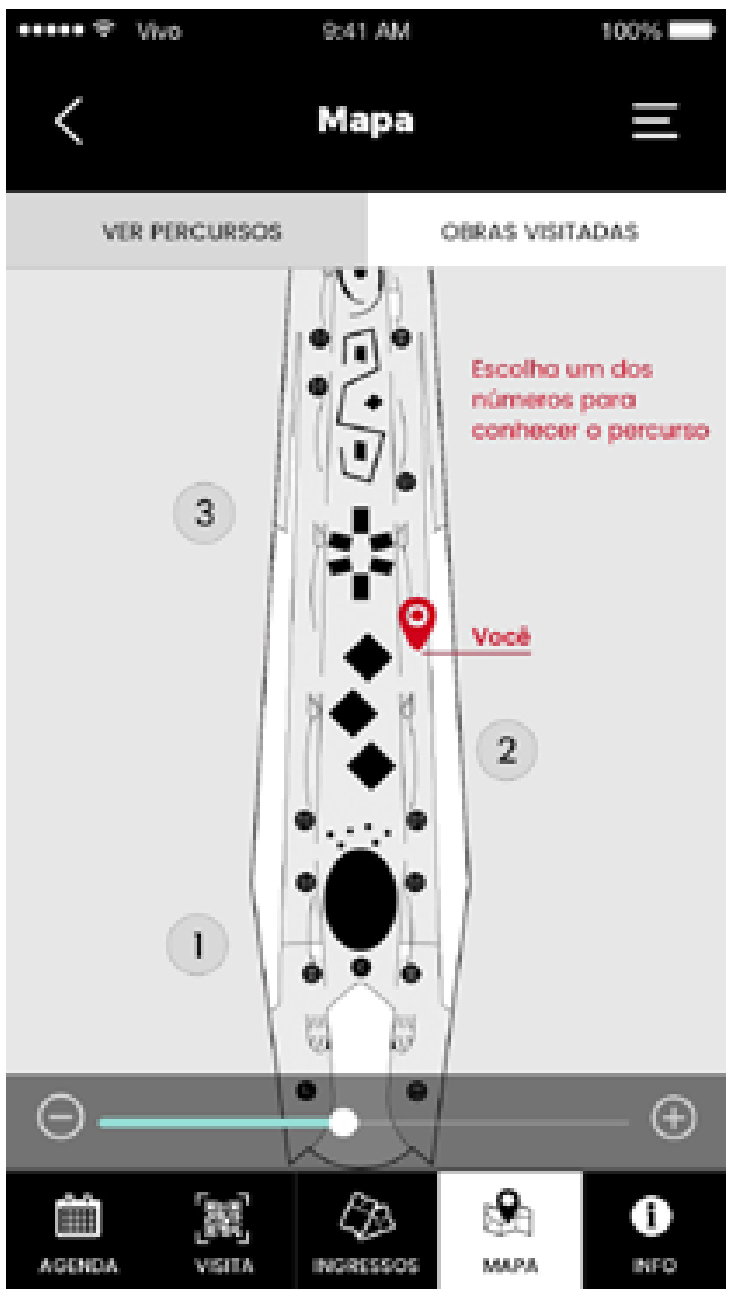

Figura 5: a) Tela exibindo o histórico de obras visitadas.

(b) Tela exibindo as rotas disponíveis para os diferentes percursos narrativos

\subsection{Conteúdo complementar e personalizado}

É possível oferecer um conteúdo complementar personalizado ao visitante, por meio de notificações ativadas pelos sensores dispostos no ambiente. No protótipo desenvolvido, essa funcionalidade é demonstrada por meio de notificações que oferecem sugestões de rotas. Como é possível ver na figura 6(a), a notificação foi ativada por um sensor localizado na entrada do museu, onde é possível cumprimentar o visitante, iniciando assim sua visita. A localização do sensor vai determinar o tipo de mensagem a ser enviada ao aplicativo do visitante.

Também é possível oferecer um conteúdo complementar em formato multimídia, que pode facilitar o entendimento da exposição, como demonstrado na figura 6(b). Essa funcionalidade pode se apresentar também em forma de mensagens de áudio, sendo de auxílio, principalmente a pessoas com deficiência visual, ou inclusive, em conjunto com ferramentas de tradução, apresentar conteúdo em outras línguas, especialmente em LIBRAS, para deficientes auditivos. 

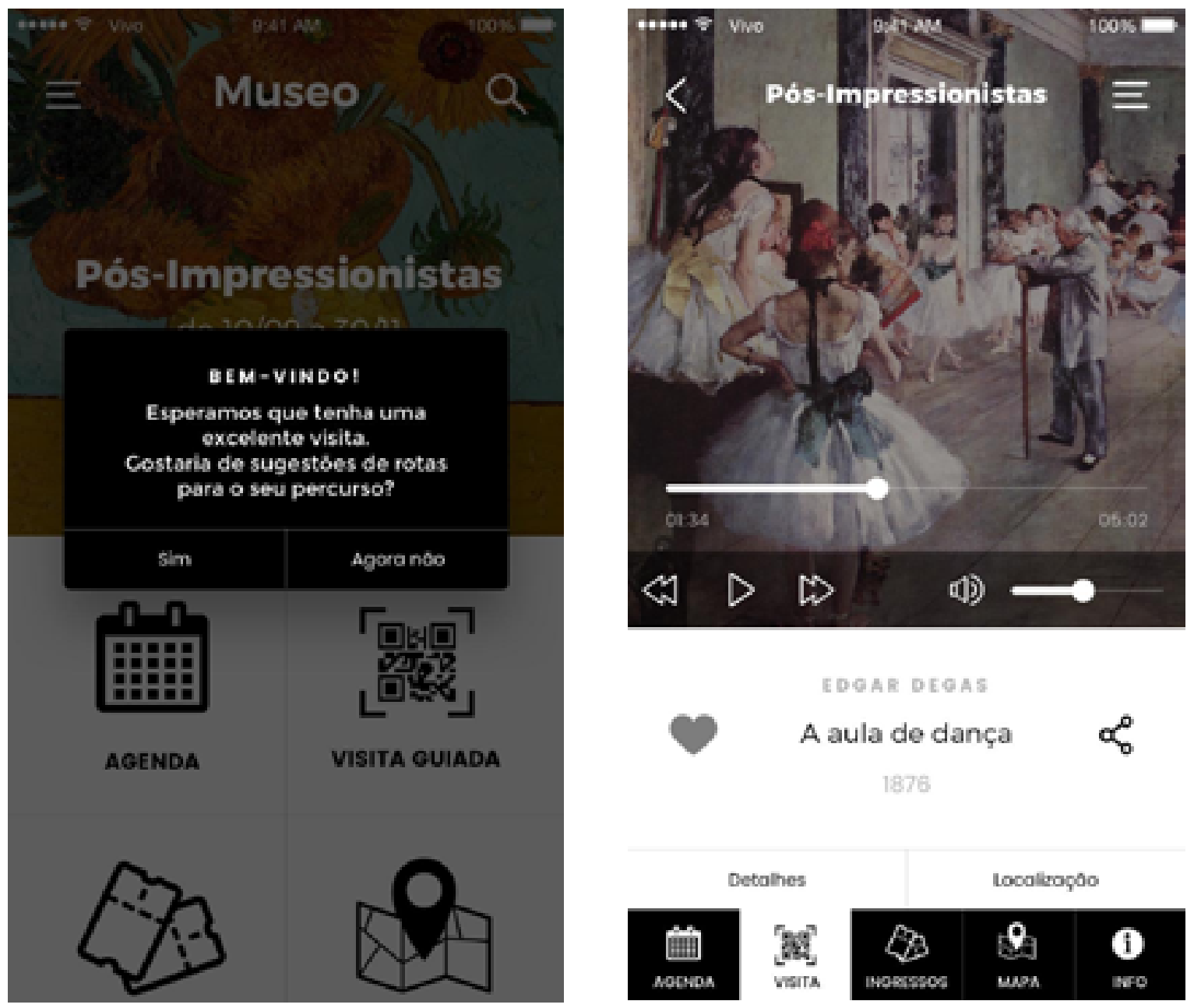

Figura 6: a) Tela exibindo a notificação ativada pelo sensor.

(b) Tela exibindo conteúdo multimídia complementar.

\subsection{Interatividade}

É possível aliar o uso dos sensores de georreferenciamento com outras tecnologias a fim de proporcionar uma experiência mais interativa aos visitantes. No protótipo foi demonstrado o uso de recursos de reconhecimento de imagem como forma de acessar o conteúdo complementar. Usando esse recurso em conjunto com os sensores é possível fazer um registro do histórico de visita e traçar o percurso já percorrido pelo visitante, podendo assim sugerir novas rotas ou tipos de conteúdo. Como demonstrado na figura 7(a), o aplicativo ao verificar que a obra já constava no histórico da visita, sugere um novo tipo de conteúdo relacionado a ela.

Outra possibilidade é a criação de narrativas, com o uso de chatbots, simulando uma conversa entre o artista e o visitante, como é demonstrado na figura 7(b). É possível inclusive aliar o uso dos sensores com recursos de realidade aumentada, que além de possibilitar a visão dos objetos de forma tridimensional, pode transformar essa representação em jogo, até mesmo em formato multiplayer, incentivando a interação entre os visitantes. 

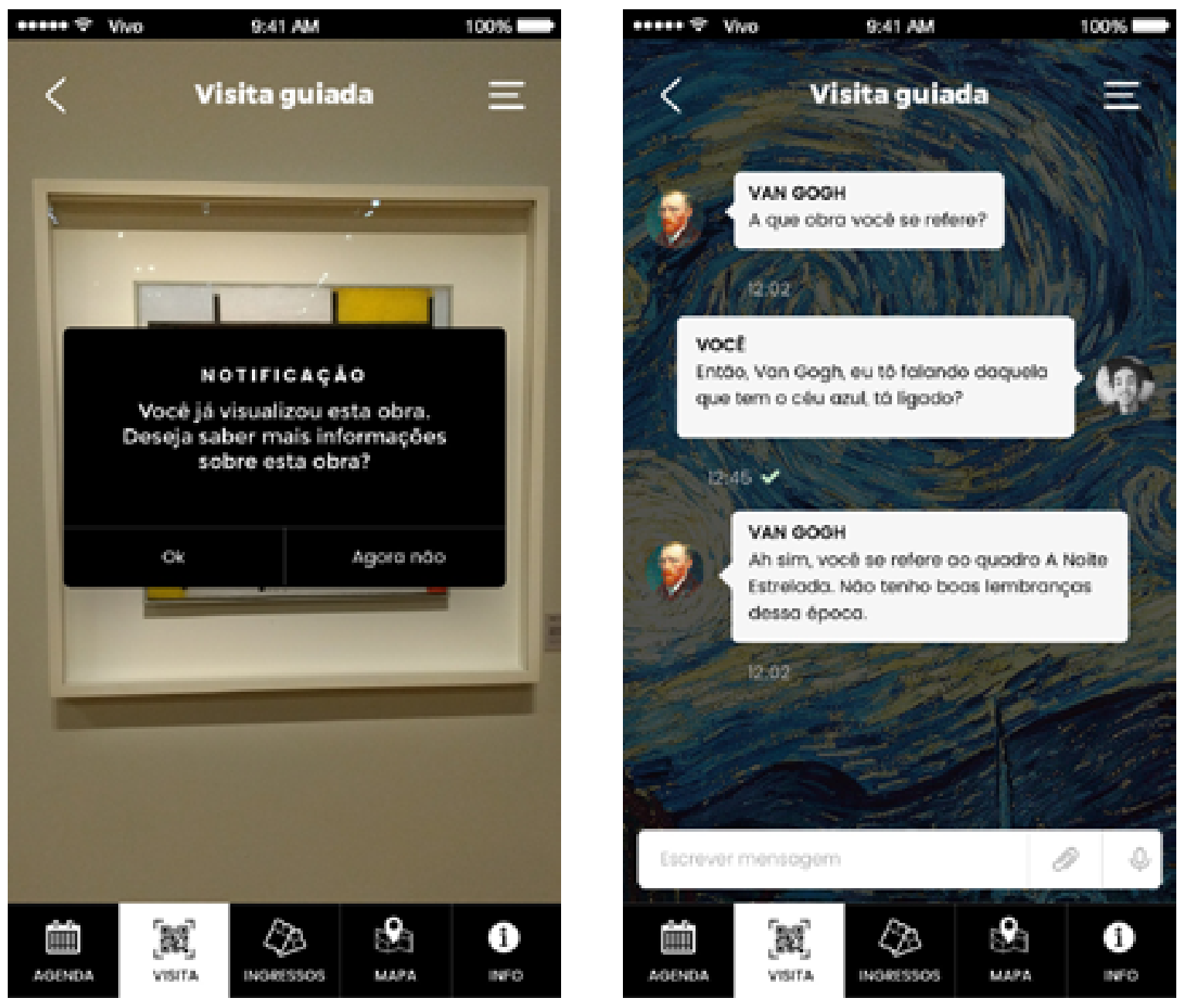

Figura 7: (a) Tela demonstrando o uso conjunto do sensor com reconhecimento de imagem.

(b) Tela demonstrando a utilização de chatbot ativado pelo sensor de georreferenciamento.

\section{Considerações Finais}

Na proposta do trabalho em que foi baseado este artigo, procurou-se verificar se $\mathrm{o}$ uso de interfaces digitais para dispositivos móveis poderia facilitar a compreensão dos elementos em exposição e a interação do visitante com o espaço expositivo.

Já o objetivo do artigo foi demonstrar as possibilidades de implementação de tecnologias ubíquas e interativas, em específico o uso de recursos de georreferenciamento no ambiente do museu. Apesar da limitação de tempo e da amostragem utilizada nas pesquisas, foi possível verificar como o uso de dispositivos móveis pode contribuir para uma visita mais inclusiva e interativa.

O acesso à cultura e à participação na criação e produção de conhecimento é direito de todos os cidadãos. O museu necessita de novas formas de dialogar com seu público integrando-se à realidade da sociedade, onde a tecnologia é parte predominante da vida das pessoas, permitindo que os visitantes sejam não apenas consumidores, mas também produtores de conteúdo. Somente assim os museus podem cumprir seu papel de instituições educadoras e culturais.

Como desdobramento futuro propõe-se um estudo mais aprofundado do tema, 
focando em acessibilidade, investigando como os sensores de georreferenciamento, podem proporcionar uma maior autonomia a pessoas com deficiência.

\section{REFERÊNCIAS}

AMARAL, Joana M. S. Guia móvel para informação em museus e instituições afins. Dissertação de Mestrado - Universidade Lusófona de Humanidades e Tecnologias, Lisboa. 2013.

ANASTÁCIO, Elisabete. O multimédia na educação museológica: uma experiência interactiva para o Museu Romântico. Dissertação de Mestrado - Faculdade de Engenharia, Universidade do Porto, Porto. 2009.

BALLARD, Barbara. Designing the mobile user experience. Chichester: John Wiley \& Sons, 2007.

BENÍCEK, Juraj. In-door localization and navigation for Android platform. Thesis Master of Applied Science - Faculty of Informatics, Masaryck University, Brno. 2015.

COSTA SANTOS, P. L. da; LIMA, F. B. Museu e suas tipologias: o webmuseu em destaque. Inf. \& Soc.:Est., João Pessoa, v.24, n.2, p. 57-68, maio/ago. 2014.

INSTITUTO BRASILEIRO DE MUSEUS (IBRAM). 10ª semana de museus: museus em um mundo em transformação: novos desafios, novas inspirações. 2012.

KRUK, Maryana. User Interface de aplicações móveis para museus: atenção partiIhada. Dissertação de Mestrado - Universidade de Lisboa, Lisboa. 2015.

LEPORACE, Camila. Aplicativo holandês transforma visita ao museu em aula interativa. 2016. http://porvir.org/aplicativo-holandes-transforma-visita-ao-museu-em-aula-interativa/. Acesso em: 14 out. 2016.

MAGALDI, Monique B. Navegando no museu virtual: um olhar sobre formas criativas de manifestação do fenômeno Museu. Dissertação de Mestrado - UNIRIO/ MAST, Rio de Janeiro. 2010.

MENEZES, Natassja. O boom de museus interativos no Rio de Janeiro: linguagem e democratização da cultura. Monografia (Graduação em Jornalismo) - ECO, UFRJ, Rio de Janeiro. 2011.

NING, JiaMin. An iBeacon-Based Location-Aware Advertising System. Thesis Master of Applied Science - University of Waterloo, Ontario. 2015. 
RUNG, M. H., LAURSEN, D. Adding to the experience: use of smartphone applications by museum visitors. In: The Transformative Museum Conference - DREAM - Danish Research Center on Education and Advanced Media Materials. Odense, Dinamarca. p. 314-324, 2002.

SWAN, Melanie. Sensor Mania! The Internet of Things, Wearable Computing, Objective Metrics, and the Quantified Self 2.0. Journal of Sensor and Actuator Networks, 2012, v.1, p.217-253. 2012.

VAZ, Roberto I. F. Interfaces tangíveis no contexto da experiência da visita a um museu: o caso do MM Gerdau - Museu das Minas e do Metal. Dissertação de Mestrado - Departamento de Comunicação e Artes - Universidade de Aveiro, Aveiro. 2014. 